\title{
The nerve lesion in the carpal tunnel syndrome
}

\author{
SYDNEY SUNDERLAND \\ From the Department of Experimental Neurology, \\ University of Melbourne, Parkville, Victoria, Australia
}

SYNOPSIS The relative roles of pressure deformation and ischaemia in the production of compression nerve lesions remain a controversial issue. This paper concerns the genesis of the structural changes which follow compression of the median nerve in the carpal tunnel. The initial lesion is an intrafunicular anoxia caused by obstruction to the venous return from the funiculi as the result of increased pressure in the tunnel. This leads to intrafunicular oedema and an increase in intrafunicular pressure which imperil and finally destroy nerve fibres by impairing their blood supply and by compression. The final outcome is the fibrous tissue replacement of the contents of the funiculi.

In 1862 Waller described the motor, vasomotor, and sensory changes which followed the compression of nerves in his own arm. His account carried no reference to the mechanism responsible for blocking conduction in the nerve fibres, presumably because he regarded it as obvious that pressure was the offending agent.

Interest in the effects of nerve compression was not renewed until the 1920 s when cuff or tourniquet compression was used to produce a reversible conduction block in the nerve. These investigations were confined to a study of the physiological effects of compression and, though they were not concerned with the pathological changes in the nerve responsible for them, they inevitably led to speculation on possible mechanisms and raised the question of whether the block was due to mechanical deformation or to ischaemia introduced by the compression.

Many concluded that ischaemia was the responsible agent (Lewis et al., 1931; Clark et al., 1935; Gasser, 1935; Grundfest, 1936; Thompson and Kimball, 1936; Wortis et al., 1942; Weddell and Sinclair, 1947; Causey and Palmer, 1949; Merrington and Nathan, 1949). Others reported characteristic differences between nerve block due to pressure and that due to ischaemia

Address for correspondence and reprints: Professor Sir Sydney Sunderland, Department of Experimental Neurology, University of Melbourne, Parkville, Victoria, 3052, Australia.

(Accepted 3 March 1976.)
(Gasser, 1935; Allen, 1938; Bentley and Schlapp, 1943; Richards, 1951; Moldaver, 1954; Gelfan and Tarlov, 1956).

In the 1940s Weiss and his associates (Weiss, 1943, 1944; Weiss and Davis, 1943; Weiss and Hiscoe, 1948), who were primarily concerned with the technical problem of uniting severed nerves, observed that a divided nerve enclosed in a tightly fitting arterial sleeve became swollen proximal and distal to the constriction. The proximal swelling was attributed to obstruction to axoplasmic flow and the distal to degenerative changes following division of the nerve. Weiss (1943) observed changes in the vascularity of the nerve but regarded these as transient. Swellings at the margins of a constriction were also observed by Causey (1948) who attributed them to the displacement of axoplasm.

The first experimental investigation directed to the histopathology of nerve compression injury was undertaken by Denny-Brown and Brenner (1944a, b). They compressed nerves in the cat by tourniquet and spring clip at pressures and for periods that were sufficient to produce a transient conduction block. Signs of damage appeared early in the compressed segment which became oedematous and infiltrated with lymphocytes and macrophages. In the spring clip experiments the compressed segment was greatly narrowed with oedematous tissue on either side of the constriction. The affected 
nerve fibres showed swelling, notching, and vacuolation of the axons, and a change in their staining qualities. The myelin showed granulation, fissuration, and vacuolation, particularly in the vicinity of the nodes and Schwann cells. These changes finally resulted in parts of the axon becoming bared or being left with only a thin coat of myelin. There was no, or very little, Schwann cell activity. The nerve fibres appeared normal below the site of compression, though beading of the axons and myelin was observed in some specimens. Conduction through the affected segment was blocked for periods of up to 19 days, and was then followed by rapid and complete recovery. Return of conductivity appeared to be associated with the remyelination of previously bared segments. However, histological changes outlasted the return of conductivity, and Denny-Brown and Brenner were uncertain whether they were ever fully corrected. They concluded that 'compression of mammalian nerve without angulation must be effective through the related ischaemia'. In arriving at this conclusion emphasis was placed on Grundfest's (1936) report that isolated frog nerve enclosed in oxygenated oil in a pressure chamber could tolerate pressures of $14,000 \mathrm{lb}$ per sq. inch before becoming inexcitable.

More recently, attention has been redirected to the structural changes associated with the experimental conduction block caused by nerve compression. Fullerton (1963) studied the effects of cuff compression in human subjects and concluded that, while the disturbances of function were due to ischaemia, the structural changes in nerve fibres were more likely the consequence of direct pressure. Subsequently, Fullerton and Gilliatt $(1967 \mathrm{a}, \mathrm{b})$ used the spontaneously occurring entrapment lesions in the median, ulnar, and plantar nerves of the guinea-pig to study the histological changes in the nerve fibres at the site of compression. Using the same model Ochoa and Marotte (1973) and Marotte (1974) extended these studies to reveal more histological detail but the essential features of the structural changes were confirmed. They concluded that the findings pointed to a mechanical rather than an ischaemic cause for the fibre damage. Nerves in the baboon have also been acutely compressed by pneumatic tourniquet (Fowler et al., 1972; Ochoa et al., 1972; Gilliatt et al., 1974) and against underlying bone by a loop of nylon cord with a weight attached (Rudge et al., 1974). From the histological changes observed in and about the compressed segment, it was concluded that the conduction block lesion was the result of direct pressure in which 'ischaemia, due to compression of the intra-neural blood vessels, plays little if any part'. Nerve fibre changes constituting a subclinical form of entrapment neuropathy have since been reported at entrapment sites in human median and ulnar nerves (Neary and Eames, 1975; Neary et al., 1975). Because of the particular importance and special significance of the recently published investigations and views of those advocating mechanical deformation as the cause of compression lesions, these are fully discussed in the epilogue at the conclusion of this paper.

The histological changes in nerves subjected 0 to chronic progressive constriction by tubing have been investigated by Weisl and Osborne (1964) and Aguayo et al. (1971). The latter reported findings that are in agreement with the observations of Ochoa and Marotte referred to earlier, with the additional note that the superficial fibres were the most severely affected, an observation later confirmed by Spinner and Spencer (1974). Aguayo and his associates were uncertain about the genesis of the lesion, believing that both ischaemia and mechanical deformation could be responsible. The account by Weisl and Osborne includes the significant comment that 'the first effect of gentle nerve compression is partial obstruction of the vasa nervorum leading to hyperaemia and oedema'. They observed that the constricted nerve became swollen proximally and distally and demonstrated that these moderately hyperaemic swellings were due, not to obstruction to axonal flow, but to the accumulation of tissue fluid between the axons. The constricted section of the nerve was oedematous and the axons narrowed. This narrowing was attributed to pressure transmitted by the fluid from the constriction device.

The behaviour of the intraneural vessels in nerves subjected to cuff compression has been investigated by Lundborg (1970). He demonstrated that the intrafunicular capillaries are more resistant to ischaemia than those in the 
epineurium, epineurial oedema appearing before any leakage occurred from the endoneurial vessels. These findings were in agreement with those reported by Olsson (1966). With continuing ischaemia the intrafunicular capillaries commenced to leak with the development of an intrafunicular oedema, which, it was stated, could be expected to not only raise the intrafunicular pressure but also alter the metabolic environment of the nerve fibres to both of which the latter are highly sensitive. The endothelial changes in the intrafunicular capillaries appeared earlier and were more severe beneath the cuff than in the ischaemic nerve below the compression. From this, Lundborg concluded that mechanical compression from the cuff was of greater significance than ischaemia in promoting those changes in the endothelium of the endoneurial capillaries which constituted the initial lesion.

As a result of these recent findings opinion has now hardened in favour of mechanical deformation being of greater significance than ischaemia in the production of compression nerve lesions resulting in prolonged conduction block. Despite the importance and significance of these new findings, they should not be divorced from their experimental setting, for it is possible that, under different conditions, the genesis of these lesions might well follow a different pattern. The possibility that additional factors and other mechanisms may operate in the production of compression lesions will now be examined using the carpal tunnel syndrome as a model.

MEDIAN NERVE LESION IN CARPAL TUNNEL SYNDROME

RELEVANT CLINICAL DATA The signs and symptoms which constitute the carpal tunnel syndrome are so well known that they do not call for comment. Some characteristic features of the condition are, however, worth recalling because of their relevance to causal mechanisms.

1. The paraesthesiae and pain in the median field which are sufficiently severe in the early hours of the morning to disturb the sleep of the patient, who obtains relief by exercising the limb.

2. The paraesthesiae and pain are aggravated, or an attack precipitated, by obstructing the venous return from the limb or arresting the circulation by a compression cuff.
3. The clumsiness of thenar movements in the morning which gradually improves during the day.

4. Swelling of the hand and digits in the morning which is relieved by exercise.

5. The immediate relief from pain which follows decompression of the carpal tunnel.

6. The failure of long-standing motor and sensory defects to improve after decompression.

RELEVANT PATHOLOGICAL DATA Information on the histopathology of the compressed segment of the nerve is limited to two accounts where necropsy material became available. Marie and Foix (1913) described a 'neuromatous' enlargement just above the retinaculum with an abrupt reduction in size in the tunnel distal to which the nerve regained its normal dimensions. The nerve bundles beneath the retinaculum were thinned with an increase in the endoneurium which had destroyed the 'myelin sheaths'. The swelling showed a considerable increase in both the epineurial and intrafunicular connective tissue though the great bulk of the swelling was due to the former. In Thomas and Fullerton's (1963) material the right nerve (marked symptoms) presented a similar picture to that reported by Marie and Foix (1913) but the left (milder symptoms) appeared normal. Histological examination of sections of both nerves from beneath the retinaculum revealed an increase in perineurial and endoneurial connective tissue and a marked reduction in the calibre of the nerve fibres.

With the exception of these two reports we are limited to observations on the appearance of the nerve in patients submitted to surgery. In the majority there is no convincing evidence of any abnormality. In this respect, however, we are ignorant of the range of normal variation in the living subject. Where there are apparent departures from the normal these follow no consistent pattern. The nerve may be enlarged immediately above the proximal margin of the retinaculum and sometimes just below its distal border. Beneath the retinaculum the nerve may be hyperaemic or constricted. Where there is gross pathology in the carpal tunnel, the nerve may be adherent to the undersurface of the retinaculum or to neighbouring structures. So variable are the findings that they give no clue to the mechanism responsible for disturbing or blocking conduction. This has been the experience of many others (Kremer et al., 1953; Garland et al., 1957; Tanzer, 1959; Kendall, 1960; Phalen, 1966).

Most attribute the nerve lesion in the carpal tunnel to compression but the role of direct pressure on the one hand and ischaemia on the other remains obscure despite the recent experimental findings in favour of the former. It is to clarify this unresolved 
issue that the next section is directed. Because of our inability to follow, in the necessary detail, all stages in the development of the lesion responsible for the condition in the human subject the best that can be expected is a reconstruction of the consequential effects of a rise in pressure in the carpal tunnel using what experimental and clinical data are available.

RELEVANT ANATOMICAL DATA At the wrist the median nerve is directly beneath the retinaculum against which it may be compressed. The crowded relations of the nerve in the confined space of the carpal tunnel with its unyielding walls immediately suggest that the nerve would be particularly vulnerable to compression in this situation. There are, however, features of the internal anatomy of the nerve trunk in this region which offer some protection to the contained nerve fibres.

FUNICULAR PATTERN In the carpal tunnel the number of bundles constituting the median nerve varies from six to 40 with an average of 24 (20 specimens, Sunderland, 1945a) while the crosssectional area of the nerve devoted to the funiculi varies from 30 to $70 \%$ with an average value of $42 \%$ (Sunderland and Bradley, 1949). With few exceptions, the median nerve in the carpal tunnel is composed of small funiculi well separated by large amounts of epineurial tissue packing. This is an arrangement which protects the nerve fibres from compression (Sunderland, 1968) so that pressures of considerable magnitude would be required to deform the funiculi and their contained nerve fibres.

PERINEURIUM Because of its tensile strength, the elastic perineurium resists and maintains an intrafunicular pressure (Sunderland, 1946, 1965; Sunderland and Bradley, 1952). There is a linear relationship between the size of a bundle and the thickness of its perineurial sheath but, in the case of the median nerve funiculi in the carpal tunnel, the perineurium is thicker than it is for bundles of the same size at other levels. The perineurium is not crossed by lymphatics and functions as a diffusion barrier. Lymphatics are confined to the epineurium and drain to regional lymph nodes.

ARRANGEMENT OF VASA NERVORUM Only capillaries are found inside the bundles. If a precapillary arteriole is present in this situation it is located in a connective tissue septum which represents the line of impending division of the funiculus or the recent union of two bundles. These capillaries are fed by arterioles and drain to venules and veins all of which are located in the epineurium; venous vessels outnumber arterial (Sunderland, 1945b; Blunt, 1959; Lundborg, 1970). The nutrient vessels take an oblique course as they pass through the perineurial sheath, thereby introducing a valve mechanism which would lead to their obstruction with any pathological swelling of the funiculus (Lundborg, 1970).

RELEVANT PHYSIOLOGICAL DATA There are at least five interrelated pressure systems in the carpal tunnel (Figure).

1. The pressure in the nutrient arteries in the epineurium $\left(\mathrm{P}^{\mathrm{A}}\right)$.

2. The capillary pressure inside the funiculi $\left(\mathrm{P}^{\mathrm{C}}\right)$.

3. The intrafunicular pressure $\left(\mathbf{P}^{\mathrm{F}}\right)$.

4. The pressure in the veins in the epineurium draining the funiculi $\left(\mathrm{P}^{\mathrm{v}}\right)$.

5. The pressure within the carpal tunnel $\left(\mathrm{P}^{\mathrm{T}}\right)$.

In order to maintain an adequate intrafunicular circulation for the nutrition of the nerve fibres, the pressure gradient across this system must be $\mathbf{P}^{\mathrm{A}}>\mathbf{P}^{\mathrm{C}}>\mathbf{P}^{\mathrm{F}}>\mathbf{P}^{\mathrm{V}}>\mathbf{P}^{\mathrm{T}}$.

\section{DISCUSSION}

If for any reason the pressure inside the tunnel, $\mathrm{P}^{\mathrm{T}}$, should increase the cushioning properties of the epineurium would protect the funiculi of the nerve from being directly affected in the early stages unless the compressing force developed rapidly and was very severe, such as could occur with traumatic dislocation of the lunate bone into the carpal tunnel. With gradually increasing pressure in the tunnel the venous channels would be the first to suffer. Pressure obstruction to the venous return from the nerve originating in this way would lead to hyperaemia, venous congestion, and circulatory slowing in the epineurial and intrafunicular tissues. With increasing pressure in the tunnel these circulatory disturbances worsen and ultimately lead, both directly and indirectly, to pathological changes in the nerve, the most damaging of which take place inside, and not external to, the funiculi. These changes would pass through the following stages.

STAGE 1 Because of the unyielding properties of the perineurium, the distension of the intrafunicular capillaries adds to the intrafunicular pressure. This, in turn, still further embarrasses the intrafunicular circulation and in this way introduces a vicious circle. As the capillary 


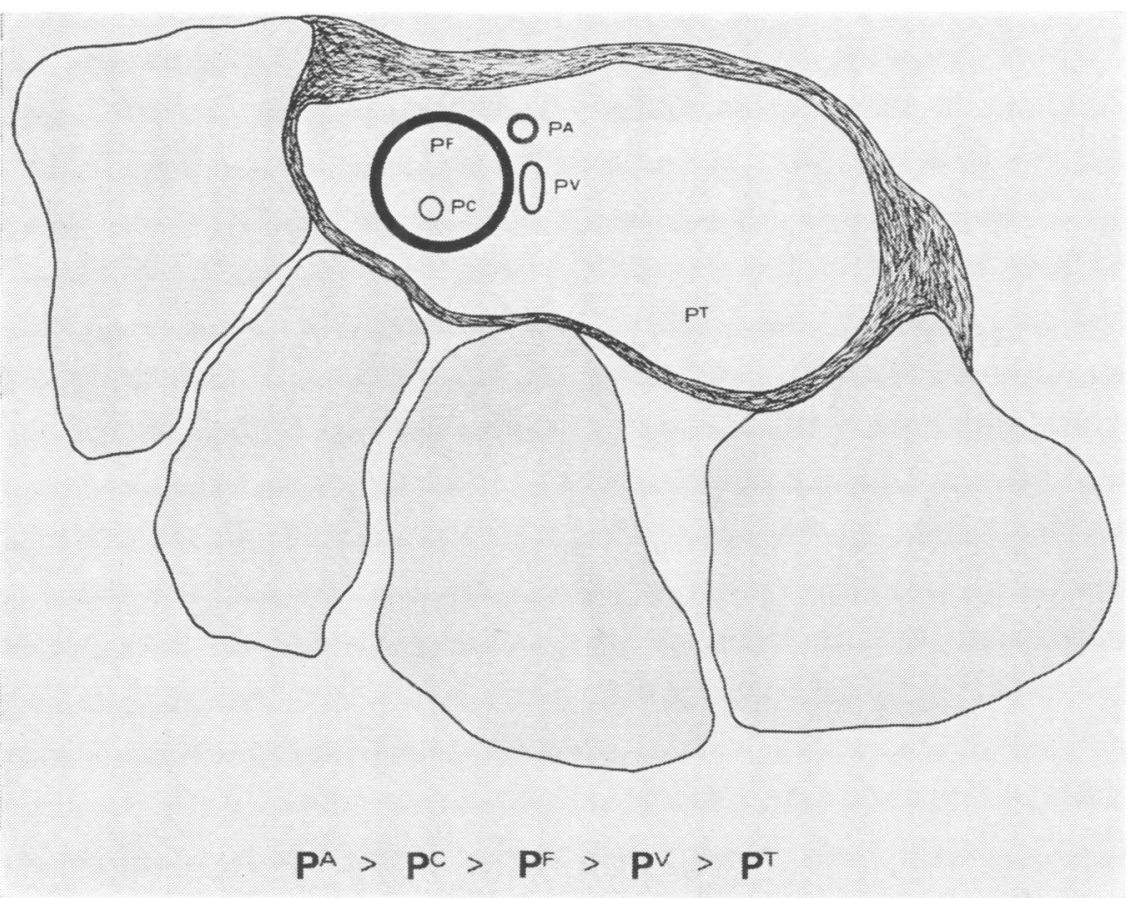

FIGURE Diagrammatic representation of one funiculus of the median nerve in the carpal tunnel with its related vessels.

circulation slows and the intrafunicular pressure rises, the incarcerated nerve fibres are compressed and their nutrition impaired to a point when, as Porter and Wharton (1949) have shown, they become hyperexcitable and start to discharge spontaneously. In this respect the large myelinated fibres are known to be more susceptible and to suffer earlier than the thin finely myelinated or non-myelinated fibres. Fibre dissociation and the imbalance in fibre activity originating in this way gives rise to pain (Noordenbos, 1959; Melzack and Wall, 1965, 1968). Thus the occurrence of paraesthesiae and pain mark the appearance of troublesome pathology, the essential lesion at this stage being caused by an impoverished intrafunicular blood supply and mild intrafunicular pressure both of which are rapidly corrected when the circulation improves. Not all funiculi or all fibres would be affected to the same degree at the same time, which explains variations in the distribution of the symptoms in the initial stages.
If for any reason the venous return from the distal part of the limb is impeded, this would aggravate the intrafunicular changes developing in the compressed segment. The appearance of disturbing nocturnal paraesthesiae and pain in the early hours of the morning could be due to the diminished return of blood from the limb. Others have directed attention to the part played by venous stasis in the production of symptoms (Kremer et al., 1953; Phalen, 1966). This has been attributed to lying on the arm (Kremer et al., 1953; Heathfield, 1957) but this would not explain the painful paraesthesiae in both hands when the condition is bilateral. A more likely explanation is the hypotonia and depression of movements during sleep (Kremer et al., 1953; Heathfield, 1957; Osborne, 1959; Phalen, 1966; Sunderland, 1968). This is supported by the measures adopted by the awakened patient to obtain relief in which the arm and hand are vigorously exercised. This activity improves the circulation by aiding venous return and reducing 
the venous congestion at the periphery. On the other hand, cuff compression, which increases the ischaemia, aggravates the condition (Gilliatt and Wilson, 1953, 1954).

At this early stage in the development of the lesion, the structural changes responsible for the symptoms are fully and rapidly corrected by any procedure directed to eliminating or reducing the pressure in the carpal tunnel. This explains the immediate relief from pain which follows operative decompression.

STAGE 2 The capillary circulation has now slowed to a point where the resulting anoxia damages the capillary endothelium, which leads to the leakage of protein into the tissues, which become oedematous. The capillaries of the epineurium are affected earlier than those inside the funiculi (Lundborg, 1970) but the accumulation of fluid is concealed within the loosely arranged epineurial tissue and any swelling is neutralized by the pressure in the tunnel.

On the other hand, the consequences are far more serious in the case of the funiculi. Here, protein steadily accumulates in the endoneurial spaces because it cannot escape across the perineurium and the endoneurial tissue becomes increasingly oedematous. This still further embarrasses conduction in the nerve fibres, and may even threaten their survival by: (1) interfering with their nutrition and metabolism; (2) compression secondary to the increase in the intrafunicular pressure which is maintained by the tensile strength of the perineurium; and, (3) promoting the proliferation and increased activity of fibroblasts with the formation of constrictive endoneurial connective tissue.

As the pressure inside the bundle increases, some swelling of the bundle may occur but this is usually held in check by the tensile strength of the perineurium to which should be added the pressure generated within the tunnel. Pressure gradients now favour the flow of endoneurial fluid centrally and distally inside the funiculi. On emerging from the tunnel, the now thinner perineurium may allow the funiculi to swell. This swelling may be concealed within the epineurium or it may be sufficient to cause the enlargements that are sometimes visible above and below the margins of the retinaculum. It might also be expected that this intrafunicular movement of fluid would occur more easily in a proximal than in a distal direction because of the superficial position occupied by the median nerve just above the retinaculum. Epineurial fluid would behave in a similar way. The overall effect of this fluid displacement would be to make the proximal enlargement on the nerve more common and larger than any associated distal swelling.

It is, therefore, intrafunicular oedema, swollen endoneurial spaces, and distended funiculi, together with epineurial oedema, which are collectively responsible for the enlargement of the nerve observed at the margins of the retinaculum. Damming of the axoplasmal flow, extrusion of axoplasm, and nodal displacement and telescoping of the axon and myelin would not, alone, be sufficient to account for the large swellings that are occasionally seen above the retinaculum. That this swelling is largely due to oedema is consistent with the observation that it may subside within minutes of decompression or by the end of the operation (Garland et al., 1957).

With these advanced structural changes the sensory and motor deficit now deepens as more and more fibres suffer a conduction block. Providing the nerve is decompressed at this? stage, the circulation is restored in the nerve and with this the oedema is gradually resolved, pressure inside the funiculi falls, and the symptoms subside. The recovery from any motor or sensory loss present before the operation is delayed depending on whether individual nerve fibres have sustained first or second degree damage.

STAGE 3 If long-standing pressure in the tunnel is allowed to continue, the lesion takes on a more permanent state. Fibroblasts start to proliferate in the protein exudate. This commencing intrafunicular fibrosis is irreversible and is associated with the destruction of increasing numbers of nerve fibres. The final stage is reached when nutrient vessels are obliterated and the affected segment of the nerve becomes converted into a fibrous cord in which only a few fine nerve fibres survive inside fibresed funiculi which are encased in a now dense relatively avascular epineurium. Attempts at regeneration through this tissue are rarely successful because 
of its length and density. Most regenerating axons terminate at the proximal margin of the retinaculum to contribute to the swelling of the nerve at that site.

With the degeneration of nerve fibres the perineurium contracts about its contents and the funiculus shrinks. The effects of this thinning on the general appearance of the nerve trunk are determined by the relative amounts of funicular and epineurial connective tissue originally constituting the nerve in the tunnel (Sunderland and Bradley, 1950a, b). Because this is a variable feature, the cross-sectional dimensions of the nerve after funicular atrophy will vary from individual to individual.

With a progressive lesion which continues to reduce the cross-sectional area of the carpal tunnel, a stage will be reached when the deforming forces generated in the tunnel (1) interfere with not only the venous return from the nerve but also the blood supply to it, and (2) contribute directly to the lesion by mechanically deforming the entire nerve trunk.

This account of the sequence of the structural changes proceeding through stages to the destruction of the conducting elements of the nerve trunk, and its conversion into a fibrous cord, is consistent with, and provides an explanation of, clinical features which are characteristic of the carpal tunnel syndrome, the appearance of nerves seen at operation, and the histological findings reported in necropsy material by Marie and Foix (1913) and Thomas and Fullerton (1963). In its scope it directs attention to changes affecting the entire nerve trunk as opposed to those affecting individual nerve fibres.

\section{EPILOGUE}

Lest what has been written in explanation of the nerve lesion in the carpal tunnel syndrome be regarded as largely speculative, the reader should be reminded that there is nothing speculative about the following.

1. The funicular structure, connective tissue packing, and arrangement of the vasa nervorum in the median nerve in the carpal tunnel.

2. The elastic and diffusion barrier properties of the perineurium, which have been exhaustively investigated and are now well documented.
3. The in-vivo studies of Lundborg on the microvascular circulation in peripheral nerves and his convincing demonstration of the endoneurial capillary leakage and endoneurial oedema which occur beneath the cuff in tourniquet compression.

4. Veins succumb to pressure before arteries.

The reconstruction of the changes representing stages in the development of the lesion, from hypoxia through intrafunicular oedema to nerve fibre destruction and collagenization, has, therefore, some basis in fact even if other links in the chain remain hypothetical. Nor does the vascular hypothesis conflict with the clinical and operative findings and the course of the recovery after decompression.

This evidence certainly justifies reopening the case in favour of a vascular origin for the nerve lesion in the carpal tunnel syndrome. The use of the term ischaemia has been carefully avoided and replaced by 'vascular' because the first changes are due to venous congestion and capillary stasis to which nerve fibres and the capillary endothelium are particularly sensitive.

It is now necessary to examine the vascular hypothesis in relation to the formidable body of evidence that has accumulated in recent years which points to mechanical deformation as the cause of the nerve damage in compression lesions and which was so admirably summarized by Gilliatt (1975) in his Oliver Sharpey Lecture.

The case for direct mechanical damage was resurrected and rejuvenated when Gilliatt and his collaborators commenced their important studies on pressure and entrapment neuropathies based on the fortuitous discovery of these spontaneous lesions in the plantar and median nerves of the guinea pig (Fullerton and Gilliatt, 1967a, b; Anderson et al., 1970). The essential histological features of the lesions were segmental demyelination of nerve fibres, some Wallerian degeneration, and evidence of regeneration. The physiological effect of the lesions was either to slow or block nerve conduction. There was only a passing reference to the condition of the other tissues comprising the nerve trunk, one of significance referring to shrunken and collagenous fascicles in a median nerve that was electrically inexcitable. The histology of this lesion closely resembles that outlined for stage 3 of a lesion due initially to 
vascular disturbances introduced by the compression.

Attention was next directed to the lesions produced experimentally by acute nerve compression (Fowler et al., 1972; Ochoa et al., 1972; Gilliatt et al., 1974; Rudge et al., 1974). Details of the structural changes observed in the compressed fibres are given in their papers. At the margins of the compression, where the pressure gradient was greatest, the large myelin fibres showed changes which included paranodal swelling, segmental demyelination, Wallerian degeneration, and a distinctive telescoping displacement of the node into the adjacent paranode in a direction away from the site of compression. These changes were associated with a greatly prolonged conduction block. The features of this nodal intussusception leave no doubt that it is produced by the direct action of deforming forces on nerve fibres. In this respect two points are worth noting.

1. The forces required to deform the nerve fibres in the manner described were of considerable magnitude, were abruptly applied, and were sustained for periods of one to three hours.

2. Tissues other than nerve fibres were not included in the study. It would, however, be surprising if forces sufficient to reach and deform well-protected nerve fibres in the manner described would leave the surrounding tissues unscathed.

These new findings raise the tempting thought that the chronic compression lesions found earlier in the guinea-pig might have a similar basis. In any event a re-examination of these lesions was undertaken (Ochoa and Marotte, 1973; Marotte, 1974). In addition, human nerves were examined in those situations where they are exposed to the risk of chronic compression-namely, the median nerve in the carpal tunnel and the ulnar nerve in the cubital tunnel (Neary and Eames, 1975; Neary et al., 1975). The conclusion from these several inquiries is that all compression lesions are due to the direct action of the deforming force on nerve fibres.

The acute compression lesion will not be considered further because the role of mechanical deformation in its production has been convincingly demonstrated. It is the chronic compression story which remains in doubt.
In their study of chronic compression Aguayo et al. (1971) reported segmental demyelination and a reduction in the number of thick myelinated fibres, but were unable to exclude ischaemia as a possible aetiological factor.

The ultrastructural studies of Ochoa and Marotte (1973) and Marotte (1974) on guineapig material revealed segmental demyelination, Wallerian degeneration, regenerating fibres, and the distortion of internodes in a manner suggestive of a mechanical origin. While arguing that the changes indicated a mechanical rather than an ischaemic cause for the nerve damage they reported the changes as being 'clearly different from those found previously in acute compression' and comment that 'in the chronic lesion, there is no displacement of the node of Ranvier'. Of particular interest, however, are the following observations on the condition of the funiculi in some of their specimens. 'The majority of the fascicles at the wrist were shrunken with a flocculant precipitate beneath a thickened perineurium. There was a loss of large diameter, fibres with increased amounts of collagen.t Again, 'in the nerve with prolonged motor latency only fibrous connective tissue appeared to be present in one fascicle from the wrist'. 'Ino the two median nerves with no response to nerve stimulation, enormously shrunken fascicles were present at the wrist which contained only a few axons devoid of myelin.' Later there is a reference to a reduced fascicular diameter compared with that of the same fascicles above and below. Marotte (1974) concluded his paper with the sentence 'It is possible that it (a proteinacious exudate) derives from vessels damaged by the compression. However, the structure of blood vessels was not studied'. While it may be claimed that these terminal changes are the end result of mechanical deformation it is equally clear that they also closely resemble lesions which have a vascular basis. Gilliatt (1975) rightly regards these as late effects and concedes that 'ischaemia may well be one of the factors responsible.'

The papers by Neary and Eames (1975) and Neary et al. (1975) between them cover essentially the same ground in that they relate to investigations into the pathology of chronic nerve compression in man, based on the examination of necropsy specimens of the median 
nerve at the wrist and the ulnar nerve at the elbow.

Neary and his associates regarded their findings as representing 'the earliest stage of a compression lesion before demyelination and degeneration has occurred'. This consisted of a distortion of the internodes with the formation of paranodal bulbous swellings consequent on myelin slippage and the folding of myelin lamellae. This change was believed to be the precursor of segmental demyelination. However, even greater significance was attached to the observation that these paranodal bulbous swellings presented a consistent polarity in different fibres, in which the swellings were always formed at the ends of the internodes further from the centre of the lesion. These observations confirmed the earlier findings of Ochoa and Marotte (1973) and Marotte (1974). The case for mechanical deformation as the cause of the lesion largely rests on the finding of this paranodal abnormality. More advanced changes involved segmental demyelination, Wallerian degeneration, and the appearance of regenerating fibres. Because these changes were observed in nerves from subjects who were symptom free during life, the condition was called subclinical entrapment neuropathy. Neary and Eames's observations were based on three ulnar nerve necropsy specimens taken from two elderly males, aged 64 and 68 years; in one there was a clinically confirmed ulnar neuropathy. They described single fibres 'showing the characteristic abnormalities of compressive neuropathy, previously described in animals (Ochoa and Marotte, 1973)', and regarded their findings as representing 'an intermediate stage between the minimal changes of entrapment neuropathy described by Neary et al. (1975) and the severe changes in the median nerves reported by Marie and Foix (1913) and Thomas and Fullerton (1963)'.

And so emerges a convincing story so persuasively presented by Gilliatt (1975) of an unbroken sequence of changes with increasing compression, commencing with the formation of bulbous paranodal swellings, leading on to segmental demyelination, and finally terminating with telescoping of the nodal region and the degeneration of the nerve fibre. However, some loose threads remain. Segmental demyelination and Wallerian degeneration are not specific to compression neuropathies, which leaves the bulbous paranodal swellings and nodal dislocation as the backbone of the case for mechanical deformation. That nodal dislocation is due to the direct action of the deforming force on the nerve fibre is conceded, but this abnormality is specific to acute compression. What is the status of the bulbous paranodal swellings? Here several points are worth noting:

1. Since the nerve fibre is the best protected of the constituents of the nerve trunk and the venules the least, why should the former be the first to suffer when the nerve is compressed?

2. The formation of these distinctive bulbous swellings is attributed to compression on the nerve trunk. There is, however, an alternative explanation to account for the form and polarity of these swellings. Pressure developing inside the funiculi as a consequence of intrafunicular oedema induced by venous congestion and venous stasis, could displace axoplasm in both directions away from the zone of high pressure and so lead to the formation of the same type of swellings with a corresponding polarity. Consistent with both explanations is the reported narrowing of axons and a shift in the histogram to thinner fibres (Weisl and Osborne, 1964; Aguayo et al., 1971). These findings also suggest that, in the case of the reported loss of large myelinated fibres (Marotte, 1974), some of this loss could be more apparent than real.

3. Granting that this abnormality is indeed the hallmark of compression deformation, it is of interest that the majority of those found harbouring it were symptom free during life. What further changes are required to tip the balance in favour of conduction impairment and conduction block and so convert the so-called subclinical entrapment neuropathy into the clinically evident variety? Are they quantitative or qualitative in nature, or both, or do they involve the introduction of an entirely new component in the form of intrafunicular venous congestion and stasis to precipitate damaging pathology?

4. It is unfortunate that of the 14 subjects providing the nerves (Neary and Eames, two, and Neary et al., 12), 10 were aged 60 years or over and, of these, two were in their 80s. Could age have contributed to the changes reported? It would be interesting to know if such abnor- 
malities occur at these entrapment sites in adolescents.

5. In the 24 nerves examined by Neary and his associates, bulbous swellings having a consistent polarity in different fibres were seen in five ulnar and five median nerves, that is in less than $50 \%$ of the specimens.

6. 'In all cases the abnormalities were localized to the elbow region in the ulnar nerve and to the region of the flexor retinaculum in the median nerve' (Neary et al., 1975). This sentence could just as well read: 'In all cases the abnormalities were localized to the elbow joint in the ulnar nerve and to the wrist joint in the median nerve'. Where these nerves cross joints they are subjected to repeated traction during movements of the limb, so that forces generated in this way might have contributed to the nerve fibre abnormalities observed. Such stretching would be aggravated if the nerve were fixed to its bed by perineural adhesions. Gilliatt (1975) also notes that 'longitudinal stretching might have the same effect'.

7. Throughout these several reports, the abnormalities seen in teased nerve fibres have been the centre of attention. There is little mention of the possible effects of compression on the microvascular circulation, and where there are references to pathological changes, other than those recorded for nerve fibres, they are very revealing as the following excerpts will show (Neary and Eames, 1975). 'Endoneurial swelling was present in all cases. . . . Some of this swelling could be accounted for by an increase in the amount of oedema.' 'It was of interest that within each nerve some fascicles were more affected than others and in particular some were more oedematous.' 'Increased amounts of endoneural collagen were present in the central transverse section in all nerves.' These observations are reminiscent of those reported by Ochoa and Marotte (1973) and Marotte (1974). Such pathology looks suspiciously like the sequelae of a vascular complication.

8. A notable feature of some cases of carpal tunnel syndrome is the immediate relief of symptoms and recovery of function after decompression. The time scale of this recovery favours improvements in the circulation rather than a more time-consuming correction of structural abnormalities in nerve fibres. The exacerbations and remissions characteristic of the condition can also be explained in the same way.

Nothing has emerged from this recent work on the effects of mechanical deformation that excludes the vascular factor from precipitating those changes which represent the initial lesion in chronic compression. On the contrary, the findings contain some evidence supporting it. There is always the possibility, of course, that the compression lesion represents the combined destructive efforts of the two factors.

In conclusion, it is again emphasized that this paper is not concerned with the problem of acute nerve compression, or with compression lesions in general, but with one compression lesion in particular-namely, that involving the median nerve in the carpal tunnel in man. Circumstances elsewhere could well be different. Thus, in some entrapment situations, friction fibrosis is an even more damaging aetiological agent than compression. Those who seek a common pathogenesis for all compression lesions will search in vain, unless, of course, their efforts are directed at the molecular level.

\section{REFERENCES}

Aguayo, A., Nair, C. P. V., and Midgley, R. (1971). Experimental progressive compression neuropathy in the rabbit. Archives of Neurclogy, 24, 358-364.

Allen, F. M. (1938). Effects of ligations on nerves of the extremities. Annals of Surgery, 108, 1088-1093.

Anderson, M. H., Fullerton, P. M., Gilliatt, R. W., and Hern, J. E. C. (1970). Changes in the forearm associated with median nerve compression at the wrist in the guinea-pig. Journal of Neurology, Neurosurgery, and Psychiatry, 33, 70-79.

Bentley, F. H., and Schlapp, W. (1943). The effects of pressure on conduction in peripheral nerve. Journal of Physiology, 102, 72-82.

Blunt, M. J. (1959). The vascular anatomy of the median nerve in the forearm and hand. Journal of Anatomy, 93, 15-21.

Causey, G. (1948). The effect of pressure on nerve fibres. Journal of Anatomy, 82, 262-270.

Causey, G., and Palmer, E. (1949). The effect of pressure on nerve conduction and nerve-fibre size. Journal of Physiology, 109, 220-231.

Clark, D., Hughes, J., and Gasser, H. S. (1935). Afferent function in the group of nerve fibers of slowest conduction velocity. American Journal of Physiology, 114, 69-76. 
Denny-Brown, D., and Brenner, C. (1944a). Paralysis of nerve induced by direct pressure and by tourniquet. Archives of Neurology and Psychiatry (Chic.), 51, 1-26.

Denny-Brown, D., and Brenner, C. (1944b). Lesion in peripheral nerve resulting from compression by spring clip. Archives of Neurology and Psychiatry (Chic.), 52, 1-19.

Fowler, T. J., Danta, G., and Gilliatt, R. W. (1972). Recovery of nerve conduction after a pneumatic tourniquet: observations on the hind-limb of the baboon. Journal of Neurology, Neurosurgery, and Psychiatry, 35, 638-647.

Fullerton, P. M. (1963). The effect of ischaemia on nerve conduction in the carpal tunnel syndrome. Journal of Neurology, Neurosurgery, and Psychiatry, 26, 385-397.

Fullerton, P. M., and Gilliatt, R. W. (1967a). Pressure neuropathy in the hind foot of the guinea pig. Journal of Neurology, Neurosurgery, and Psychiatry, 30, 18-25.

Fullerton, P. M., and Gilliatt, R. W. (1967b). Median and ulnar neuropathy in the guinea-pig. Journal of Neurology, Neurosurgery, and Psychiatry, 30, 393-402.

Garland, H., Bradshaw, J. P. P., and Clark, J. M. P. (1957). Compression of median nerve in carpal tunnel and its relation to acroparaesthesiae. British Medical Journal, 1, 730-734.

Gasser, H. S. (1935). Conduction in nerves in relation to fiber types. In Sensation: its Mechanisms and Nisturbances. Proceedings of the Association of Research in Nervous and Mental Diseases, 15, 35-59.

Gelfan, S., and Tarlov, I. M. (1956). Physiology of spinal cord, nerve root and peripheral nerve compression. American Journal of Physiology, 185, 217-229.

Gilliatt, R. W. (1975). Peripheral nerve compression and entrapment. The Oliver Sharpey Lecture, February 1975. In Eleventh Symposium on Advanced Medicine. Edited by A. F. Lant. Pitman Medical: London.

Gilliatt, R. W., McDonald, W. I., and Rudge, P. (1974). The site of conduction block in peripheral nerves compressed by a pneumatic tourniquet. Journal of Physiology, 238, 31P-32P.

Gilliatt, R. W., and Wilson, T. G. (1953). A pneumatictourniquet test in the carpal-tunnel syndrome. Lancet, 2, 595-597.

Gilliatt, R. W., and Wilson, T. G. (1954). Ischaemic sensory loss in patients with peripheral nerve lesions. Journal of Neurology, Neurosurgery, and Psychiatry, 17, 104-114.

Grundfest, H. (1936). Effects of hydrostatic pressures upon the excitability, the recovery and the potential sequence of frog nerve. Cold Spring Harbor Symposia on Quantitative Biology, 4, 179-187.

Heathfield, K. W. G. (1957). Acroparaesthesiae and the carpal-tunnel syndrome. Lancet, 2, 663-666.

Kendall, D. (1960). Aetiology, diagnosis, and treatment of paraesthesiae in the hands. British Medical Journal, $2,1633-1640$.
Kremer, M., Gilliatt, R. W., Golding, J. S. R., and Wilson, T. G. (1953). Acroparaesthesiae in the carpaltunnel syndrome. Lancet, 2, 590-595.

Lewis, T., Pickering, G. W., and Rothschild, P. (1931). Centripetal paralysis arising out of arrested blood-flow to the limb, including notes on a form of tingling. Heart, 16, 1-32.

Lundborg, G. (1970). Ischemic Nerve Injury. Erlanders Biktryckeri Actiebolag: Göteborg.

Marie, P., and Foix (1913). Atrophie isolée de l'éminence thénar d'origine névritique. Rôle du ligament annulaire antérieur du carpe dans la pathogénie de la lésion. Révue Neurologique, 26, 647-649.

Marotte, L. R. (1974). An electron microscope study of chronic median nerve compression in the guinea-pig. Acta Neuropathologica (Berlin), 27, 69-82.

Melzack, R., and Wall, P. D. (1965). Pain mechanisms: A new theory. Science, 150, 971-979.

Melzack, R., and Wall, P. D. (1968). Gate control theory of pain. In Pain. Edited by A. Soulairac, J. Cahn, and J. Charpentier. Academic Press: London.

Merrington, W. R., and Nathan, P. W. (1949). A study of post-ischaemic paraesthesiae. Journal of Neurology, Neurosurgery, and Psychiatry, 12, 1-18.

Moldaver, J. (1954). Tourniquet paralysis syndrome. Archives of Surgery (Chic.), 68, 136-144.

Neary, D., and Eames, R. A. (1975). The pathology of ulnar nerve compression in man. Neuropathology and Applied Neurobiology, 1, 69-88.

Neary, D., Ochoa, J., and Gilliatt, R. W. (1975). Subclinical entrapment neuropathy in man. Journal of the Neurological Sciences, 24, 283-298.

Noordenbos, W. (1959). Pain. Elsevier: Amsterdam.

Ochoa, J., Fowler, T. J., and Gilliatt, R. W. (1972). Anatomical changes in peripheral nerves compressed by a pneumatic tourniquet. Journal of Anatomy, 113, 433-455.

Ochoa, J., and Marotte, L. R. (1973). The nature of the nerve lesion caused by chronic entrapment in the guinea-pig. Journal of Neurological Sciences, 19, 491-495.

Olsson, Y. (1966). Studies on vascular permeability in peripheral nerves. 1. Distribution of circulating fluorescent serum albumin in normal, crushed and sectioned peripheral nerve. Acta Neuropathologica (Berlin), 7, 1-15.

Osborne, G. (1959). Acroparaesthesia and the carpal tunnel. British Medical Journal, 2, 98.

Phalen, G. S. (1966). The carpal-tunnel syndrome. Journal of Bone and Joint Surgery, 48-A, 211-228.

Porter, E. L., and Wharton, P. S. (1949). Irritability of mammalian nerve following ischemia. Journal of Neurophysiology, 12, 109-116.

Richards, R. L. (1951). Ischaemic lesions of peripheral nerves: A review. Journal of Neurology, Neurosurgery, and Psychiatry, 14, 76-87. 
Rudge, P., Ochoa, J., and Gilliatt, R. W. (1974). Acute peripheral nerve compression in the baboon. Journal of Neurological Sciences, 23, 403-420.

Spinner, M., and Spencer, P. S. (1974). Nerve compression lesions of the upper extremity. Clinical Orthopaedics and Related Research, 104, 46-67.

Sunderland, S. (1945a). The intraneural topography of the radial, median and ulnar nerves. Brain, 68, 243-299

Sunderland, S. (1945b). Blood supply of the nerves of the upper limb in man. Archives of Neurology and Psychiatry (Chic.), 53, 91-115.

Sunderland, S. (1946). The effect of rupture of the perineurium on the contained nerve fibres. Brain, 69, 149-152.

Sunderland, S. (1965). The connective tissues of peripheral nerves. Brain, 88, 841-853.

Sunderland, S. (1968). Nerves and Nerve Injuries. Livingstone: Edinburgh.

Sunderland, S., and Bradley, K. C. (1949). The crosssectional area of peripheral nerve trunks devoted to nerve fibres. Brain, 72, 428-449.

Sunderland, S., and Bradley, K. C. (1950a). Denervation atrophy of the distal stump of a severed nerve. Journal of Comparative Neurology, 93, 401-409.

Sunderland, S., and Bradley, K. C. (1950b). Endoneurial tube shrinkage in the distal segment of a severed nerve. Journal of Comparative Neurology, 93, 411-420.

Sunderland, S., and Bradley, K. C. (1952). The perineurium of peripheral nerves. Anatomical Record, 113, 125-142.

Tanzer, R. C. (1959). The carpal-tunnel syndrome: A clinical and anatomical study. Journal of Bone and Joint Surgery, 41-A, 626-634.
Thomas, P. K., and Fullerton, P. M. (1963). Nerve fibre size in the carpal tunnel syndrome. Journal of Neurology, Neurosurgery, and Psychiatry, 26, 520-527.

Thompson, I. M., and Kimball, H. S. (1936). Effect of local ischemia upon human nerve fibers in vivo. Proceedings of the Society for Experimental Biology and Medicine, 34, 601-603.

Waller, A. (1862). On the sensory, motory, and vasomotory symptoms resulting from refrigeration and compression of the ulnar and other nerves in man. Proceedings of the Royal Society, 12, 89-103.

Weddell, G., and Sinclair, D. C. (1947). 'Pins and needles': Observations on some of the sensations aroused in a limb by the application of pressure. Journal of Neurology, Neurosurgery, and Psychiatry, 10, 26-46.

Weisl, H., and Osborne, G. V. (1964). The pathological changes in rats' nerves subject to moderate compression. Journal of Bone and Joint Surgery, 46B, 297-306.

Weiss, P. (1943). Endoneurial edema in constricted nerve. Anatomical Record, 86, 491-522.

Weiss, P. (1944). Damming of axoplasm in constricted nerve; a sign of perpetual growth in nerve fibres. Anatomical Record, 88, 464.

Weiss, P., and Davis, H. (1943). Pressure block in nerves provided with arterial sleeves. Journal of Neurophysiology, 6, 269-286.

Weiss, P., and Hiscoe, H. B. (1948). Experiments on the mechanism of nerve growth. Journal of Experimentake Zoology, 107, 315-395.

Wortis, H., Stein, M. H., and Jolliffe, N. (1942). Fiber dissociation in peripheral neuropathy. Archives of Internal Medicine, 69, 222-237. 